\title{
Functional Surfaces with Photocatalytic Behavior and Reversible Wettability: ZnO Coating on Silicon Spikes
}

\author{
Melani A. Frysali, ${ }^{\dagger,}$ Lampros Papoutsakis, ${ }^{\dagger}$ George Kenanakis, ${ }^{\dagger}$ and Spiros H. Anastasiadis $*, \dagger$ \\ ${ }^{\dagger}$ Institute of Electronic Structure and Laser, Foundation for Research and Technology - Hellas, P.O. Box 1385, 711 10 Heraklion, \\ Crete, Greece \\ ${ }^{\ddagger}$ Department of Chemistry, University of Crete, P.O. Box 2208, 71003 Heraklion, Crete, Greece
}

\begin{abstract}
Multifunctional surfaces with reversible characteristics have gained great attention due to their various envisioned applications. We report on the development of surfaces exhibiting both photocatalytic activity and reversible wettability. Initially, irradiation of silicon wafers with femtosecond laser pulses produces a surface with dual-scale roughness in the micro- and nanoscale. Subsequently, the hierarchically roughened silicon surfaces are coated with $\mathrm{ZnO}$ following a simple solgel process. The manufactured artificial surfaces exhibit reversible wettability from superhydrophilic (upon UV irradiation) to superhydrophobic (upon heating), while the specimens reveal high photocatalytic activity as illustrated by the decolorization of methylene blue utilized as a model dye. The surfaces exhibit reproducibility and stability over a number of cycles.
\end{abstract}

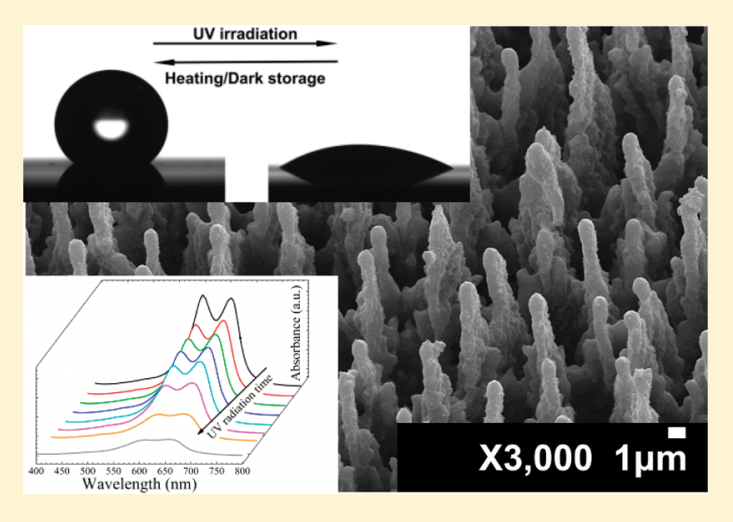

\section{INTRODUCTION}

Self-cleaning surfaces have gained the focus of considerable research due to their strong potential for exploitation in a number of industrial applications. ${ }^{1}$ Superhydrophobic materials can be widely used in outdoor weather-proof paints, easy-toclean textiles, microfluidics, lab-on-chip devices, low friction coatings (e.g., for ships), and solar panels. In most cases, when superhydrophobicity is discussed, one means surfaces with high contact angles $\left(>150^{\circ}\right)$ and low contact angle hysteresis (or sliding angles) with water droplets being able to roll off easily from the surfaces; ${ }^{2-6}$ in those cases, the surfaces exhibit water repellency $^{3-5,7-9}$ and are frequently described as superhydrophobic with low adhesion. However, there are many naturally occurring surfaces that exhibit high contact angles $\left(>150^{\circ}\right)$ together with high contact angle hysteresis $\left(>90^{\circ}\right)$; these surfaces are called superhydrophobic with high adhesion. $^{10-12}$ As the flip side of the coin, superhydrophilic surfaces are used in the cleaning of roof tiles and windows, in mist-free mirrors, and in photochemical degradation, to name but a few applications. ${ }^{13}$ The inspiration for designing and developing new self-cleaning materials comes from nature; ${ }^{1}$ the Lotus effect, which results in superhydrophobicity and very high water repellency, as exhibited by the leaves of sacred Lotus (Nelumbo nucifera), was first reported by Barthlott and Neinhuis. ${ }^{14,15}$ Apart from this, there is a wide variety of biological species exhibiting amazing properties, like rice leaves, rose petals, the strider's legs, gecko feet, shark skin, mosquito compound eye, spider silks, and cicada and butterfly wings. ${ }^{16}$

The most common way to generate effective superhydrophobic surfaces is to build multiscale hierarchical roughness. One way this can be achieved is by micro/ nanostructruring a surface utilizing ultrafast lasers, which creates dual scale roughness in a one-step process. ${ }^{3,17}$ The first conical microstructures with multiscale roughness were reported by Her and Mazur ${ }^{18}$ in 1998. Since then, femtosecond laser has proven to be a promising method for fabricating hierarchical structures with multiscale roughness. ${ }^{19}$ For example, Zorba et al. produced artificially structured surfaces possessing controlled dual-scale roughness, which exhibited the water repellent characteristics of the natural Lotus leaf. f $^{3,21}$

Moreover, there is a continuously increasing demand for multifunctional surfaces with reversible characteristics. This can be achieved by using "smart" coatings, which can respond to external stimuli, such as light, ${ }^{22-26}$ temperature, ${ }^{22,27-29}$ electric field, ${ }^{22,29-31} \mathrm{pH}^{22,32-34}$ or solvent selectivity. ${ }^{22,34}$ Among them, the wetting properties of $\mathrm{ZnO}$ have been widely studied, since it can reversibly switch from superhydrophilic to superhydrophobic in response to UV irradiation and heating or dark storage, respectively. ${ }^{35-37}$ For example, Papadopoulou et al. reported the preparation of photoreversible $\mathrm{ZnO}$ hierarchical surfaces prepared by irradiating $\mathrm{Si}$ substrates with femtosecond laser and decorating them with $\mathrm{ZnO}$ nanoprotrusions using pulsed laser deposition. ${ }^{35}$

Furthermore, $\mathrm{ZnO}$ is a well-known photocatalyst. In order to enhance its photocatalytic activity, research efforts have focused on the development of $\mathrm{ZnO}$ surfaces with a high surface to volume ratio. Among those, $\mathrm{ZnO}$ nanorods, ${ }^{37,38}$ nanoflowers, ${ }^{39}$ nanobelts, and nanowires ${ }^{40}$ have been reported, which can be

Received: August 9, 2015

Revised: October 10, 2015

Published: October 16, 2015 

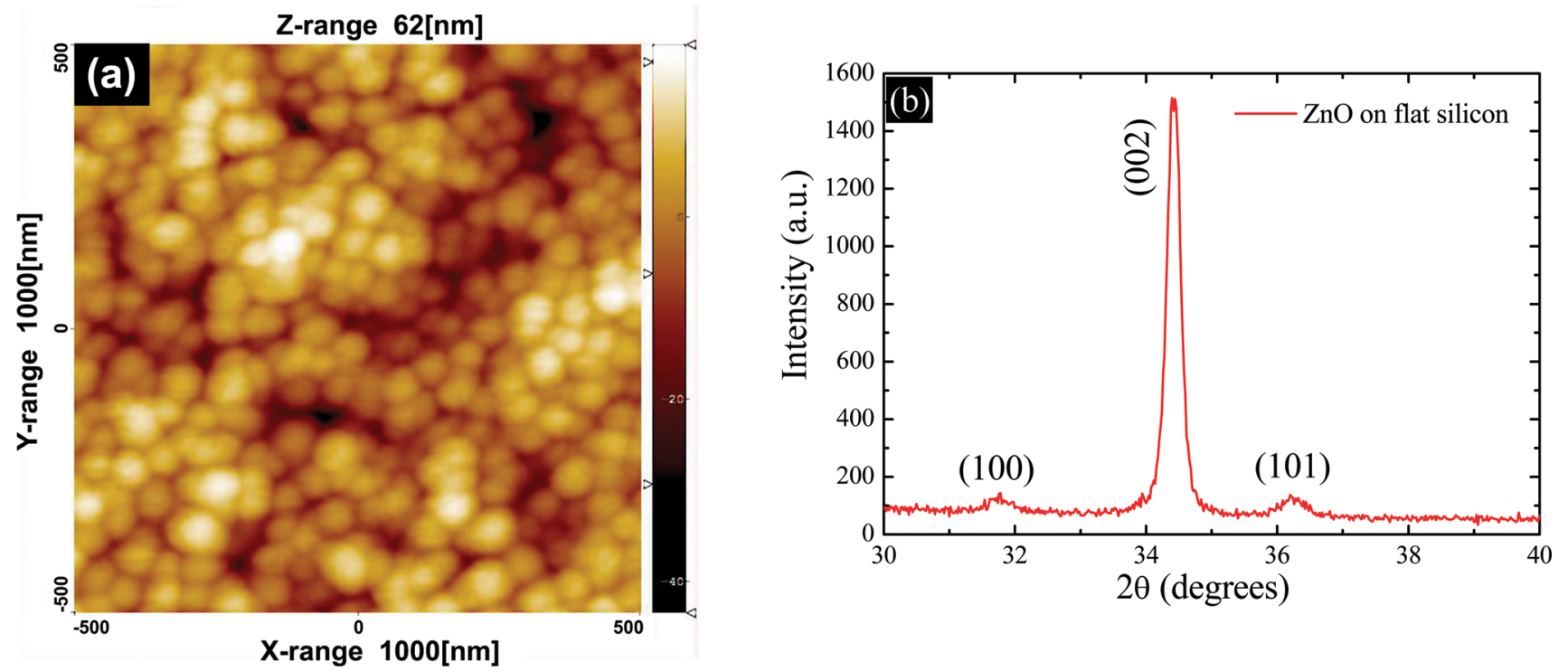

Figure 1. AFM image (scan size $1 \mu \mathrm{m} \times 1 \mu \mathrm{m}$; $z$-range $\sim 62 \mathrm{~nm}$ ) (a) and X-ray diffractogram (b) of a $\sim 80$-nm-thick $\mathrm{ZnO}$ film on a flat silicon substrate.

easily produced by a simple sol-gel method followed by hydrothermal synthesis or other approaches. ${ }^{37,41}$ However, most of the work cited above suffers from the disadvantage of producing low stability specimens, which cannot be easily adopted for large-scale synthesis and, thus, for industrial applications.

The research efforts up to now have focused on either superhydrophobic photocatalytic $\mathrm{ZnO}$ surfaces or superhydrophilic photocatalytic self-cleaning surfaces. The combination of surfaces exhibiting reversible wettability behavior (from superhydrophobic to superhydrophilic) together with excellent photocatalytic activity is an innovative point of view, since such smart surfaces can reduce the maintenance costs and save time. In this work, we report the development of $\mathrm{ZnO}$ coatings exhibiting reversible wettability and photocatalytic activity. These are prepared following a two-step fabrication process. First, silicon $(\mathrm{Si})$ wafers are irradiated with femtosecond (fs) laser pulses in order to produce $\mathrm{Si}$ surfaces with dual scale roughness ( $\mathrm{Si}$ spikes). ${ }^{3,20,21}$ Then, the rough $\mathrm{Si}$ samples are coated with a $\mathrm{ZnO}$ film prepared by a simple sol-gel process. ${ }^{41-43}$ The artificial surfaces exhibit reversible wettability from superhydrophilic (upon UV irradiation) to superhydrophobic (upon heating), while the as-grown samples revealed high photocatalytic activity investigated by means of the decolorization of methylene blue as a model dye. The reproducibility and sustainability of the system is thoroughly studied. To the best of our knowledge, this is the first investigation referring to $\mathrm{ZnO}$ surfaces on $\mathrm{Si}$ spikes, which illustrate both high photocatalytic activity and reversible wettability from superhydrophobic to superhydrophilic.

\section{EXPERIMENTAL SECTION}

Surface Manufacturing. The fabrication of Si spikes with a $\mathrm{ZnO}$ coating was achieved following a two-step process: First, single crystal $n$-type $\mathrm{Si}(100)$ wafers with a resistivity of $\rho=2-8$ $\Omega \cdot \mathrm{cm}$ were placed in a vacuum chamber under a pressure of $10^{-2}$ mbar (which is drained with a reactive gas $\left(\mathrm{SF}_{6}\right)$ atmosphere at a pressure of 500 Torr) and irradiated using a $\mathrm{Yb}: \mathrm{KGW}$ laser with a repetition rate of $1 \mathrm{kHz}$ and a pulse duration of $170 \mathrm{fs}$ at a wavelength of $1026 \mathrm{~nm}$, while the laser pulse fluence was maintained at $0.65 \mathrm{~J} / \mathrm{cm}^{2}$. The chamber was mounted on a high precision $\mathrm{X}-\mathrm{Y}$ translational stage and the sample surface was kept perpendicular to the incident laser beam. The stage motion was synchronized with a mechanical shutter in order to provide a uniform exposure of a $100 \mathrm{~mm}^{2}$ area to an average of 500 laser pulses per spot. After that, the samples were cleaned with a $10 \%$ HF aqueous solutions in order to remove the silicon oxide grown on the surface. $3,20,21$

After rinsing several times with ethanol and bidistilled water in order to remove any remains, the surfaces were coated by a $\mathrm{ZnO}$ film using a simple sol-gel process. ${ }^{41-43}$ For this purpose, Zinc acetate dihydrate $\left[\left(\mathrm{Zn}\left(\mathrm{CH}_{2} \mathrm{COO}\right)_{2} \cdot 2 \mathrm{H}_{2} \mathrm{O}\right)\right.$, SigmaAldrich, 99.99\%] was dissolved in 2-methoxy ethanol $\left[\left(\mathrm{CH}_{3} \mathrm{OCH}_{2} \mathrm{CH}_{2} \mathrm{OH}\right)\right.$, Sigma-Aldrich, $\left.\geq 99.55 \%\right]$ at a concentration of $0.75 \mathrm{~mol} / \mathrm{L}$. Monoethanolamine [ $\left(\mathrm{HOCH}_{2} \mathrm{CH}_{2} \mathrm{NH}_{2}\right)$, Sigma-Aldrich, $\left.\geq 99.0 \%\right]$ was also added as a stabilizer and the molar ratio of zinc acetate to ethanolamine was kept at 1:1. The resultant solution was stirred for $1 \mathrm{~h}$ at $60{ }^{\circ} \mathrm{C}$ in order to become homogeneous. Subsequently, $30 \mu \mathrm{L}$ of the solution were dropped on the laser irradiated Si samples, which were rotated at $3000 \mathrm{rpm}$ for $20 \mathrm{~s}$. After coating, the samples were heated at $350{ }^{\circ} \mathrm{C}$ for $10 \mathrm{~min}$ to evaporate the solvent and remove any organic residue. This procedure was repeated four $(4 \times)$ times. Finally, the samples were annealed in air at $500{ }^{\circ} \mathrm{C}$ for $1 \mathrm{~h}$. In parallel with the deposition of the $\mathrm{ZnO}$ coatings on Si spikes, $\mathrm{ZnO}$ films on flat silicon wafers were grown as well. This way, reference specimens of $\mathrm{ZnO}$ on flat silicon were created for reference and comparison reasons.

Surface Characterization. The surface morphology of flat $\mathrm{Si}$ substrates coated with $\mathrm{ZnO}$ films was investigated using an atomic force microscope (AFM) in tapping mode (Digital instruments - Nanoscope IIIa). The grain size and the roughness ( $\mathrm{rms}$ ) of the $\mathrm{ZnO}$ films on flat $\mathrm{Si}$ wafers were determined using the scanning probe image processing software (SPIP, v 3.3.5.0, Image Metrology) for nano- and microscale microscopy, while the thickness of the $\mathrm{ZnO}$ film was measured with a stylus profilometer (alpha-step 100, Tencor). The morphology of laser irradiated Si surfaces, with and without the $\mathrm{ZnO}$ coating, was studied using a field emission scanning 

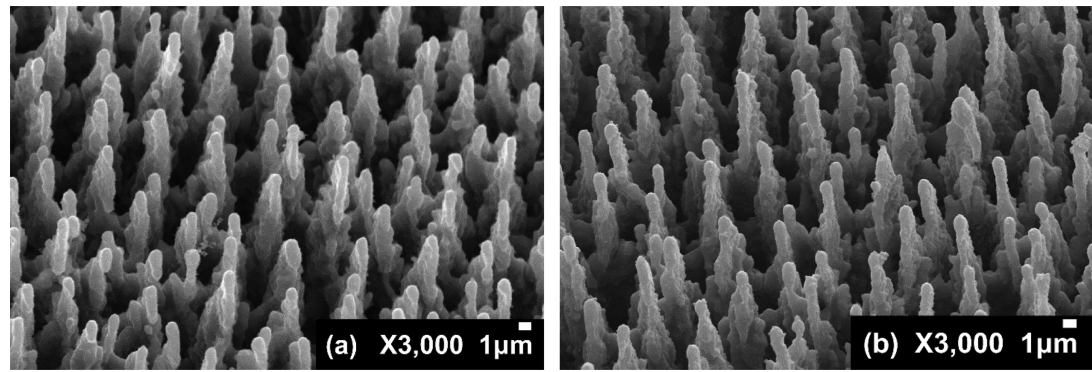

Figure 2. FE-SEM micrographs of bare Si spikes prepared by femtosecond laser irradiation on silicon (a) and coated with $\mathrm{ZnO}$ by the sol-gel/spincoating process $(\mathrm{b})$.
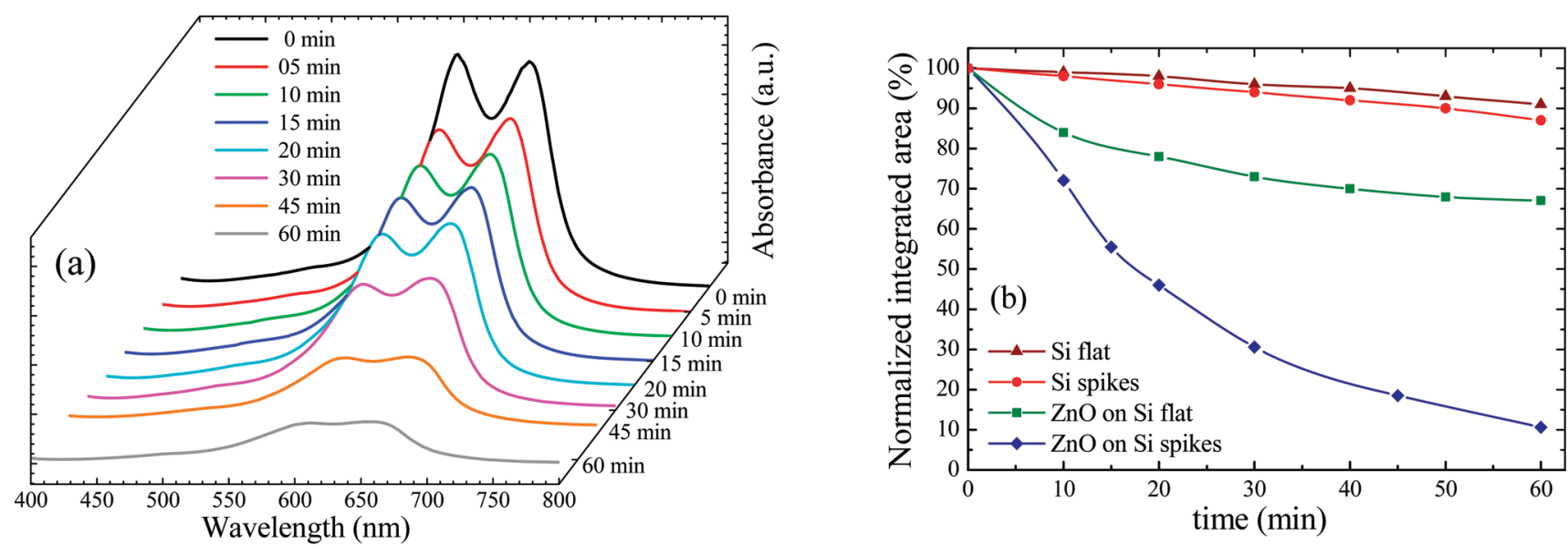

Figure 3. (a) UV-vis absorption spectra of aqueous solution of methylene blue in contact with a surface with a $\mathrm{ZnO}$ coating on top of silicon spikes following UV irradiation for various times. (b) Normalized absorption of aqueous solutions of methylene blue at $\lambda_{\max }=665 \mathrm{~nm}$ under UV light irradiation, for flat $\mathrm{Si}$ substrate (triangles), Si spikes (circles), $4 \times \mathrm{ZnO}$ coating on flat silicon (squares), and $4 \times \mathrm{ZnO}$ coating on silicon spikes (diamonds), respectively.

electron microscope (FE-SEM, JEOL JSM-7000F), while the crystalline structure of all samples was determined by X-ray diffraction (XRD) utilizing a Rigaku (RINT 2000) diffractometer with $\mathrm{Cu} \mathrm{K} \alpha$ radiation with a wavelength $\lambda=1.54 \AA$.

Photocatalysis. The photocatalytic activity of the samples was quantified by means of the decolorization of methylene blue $(\mathrm{MB})$ in aqueous solution at an initial concentration of 5.4 $\times 10^{-7} \mathrm{~mol} / \mathrm{L}(20 \mathrm{ppm})$, which is a typical potent cationic dye that has been widely used as a model organic probe to test the photocatalytic performance of photocatalysts. ${ }^{44-47}$ The studied samples (both $\mathrm{ZnO}$ coated and bare Si spikes) were placed in a custom-made quartz cell, and the whole setup was illuminated for up to $60 \mathrm{~min}$ using a UV lamp centered at $365 \mathrm{~nm}$ (Philips HPK $125 \mathrm{~W}$ ) with a light intensity of $\sim 10 \mathrm{~mW} / \mathrm{cm}^{2}$. The MB concentration was monitored during decolorization by UV-vis spectroscopy in absorption mode, using a PerkinElmer (Lambda 950) spectrophotometer over the wavelength range of 250-1100 nm. In addition, an apparent rate constant $(k)$ has been calculated as the basic kinetic parameter for the comparison of the photocatalytic activities. The rate constant $k$ was obtained by fitting the concentration data to an equation

$$
\ln \left(C_{t} / C_{0}\right)=-k t
$$

where $k$ is apparent rate constant, $C_{\mathrm{t}}$ is the actual concentration at time $t$, and $C_{0}$ the initial concentration of MB. Since methylene blue has a strong absorption peak at $\lambda_{\max }=665 \mathrm{~nm}$, a series of $\mathrm{MB}$ aqueous solutions of known concentration were prepared first in order to build a calibration curve. Photolysis experiments were also performed using bare $\mathrm{Si}$ substrates and bare Si spikes, under exactly the same conditions applied for the $\mathrm{ZnO}$ coated surfaces.

Wettability. Wettability tests were performed using a surface tensiometer (OCA-40, Dataphysics) utilizing the sessile drop method. ${ }^{48}$ A drop of $5 \mu \mathrm{L}$ was deposited on the surface of each substrate after exposure to the UV lamp or heating at 200 ${ }^{\circ} \mathrm{C}$ and the contact angle was measured in each case. Digital images of the water droplets were taken and the water contact angle was calculated by fitting the whole drop profile using Bashforth-Adams equation, thus evaluating both the contact angle and the surface tension of the fluid.

\section{RESULTS AND DISCUSSION}

Artificial Surface Characterization. An AFM image of a $4 \times$ layered $\mathrm{ZnO}$ film on a flat $\mathrm{Si}$ wafer is shown in Figure 1a, with a scanned surface area of $1 \mu \mathrm{m}^{2}$. The thickness of the film was $\sim 80 \mathrm{~nm}$ estimated with the stylus profilometer. The determined rms roughness of the film is $\sim 9.5 \mathrm{~nm}$ while the grain size is estimated as $\sim 36.5 \pm 2 \mathrm{~nm}$. Figure $1 \mathrm{~b}$ depicts a typical X-ray diffraction pattern of the $\mathrm{ZnO}$ thin films deposited on silicon by the sol-gel/spin-coating technique after 4 spinning cycles and annealing at $500{ }^{\circ} \mathrm{C}$. XRD pattern reveals a strong (002) peak at a diffraction angle of $2 \theta=34.42^{\circ}$ and two more at $31.78^{\circ}$ and $16.20^{\circ}$, which correspond to the (100) and (101) planes, respectively, in good agreement with the JCPDS card (No. 36-1451) for a typical hexagonal wurtzite type $\mathrm{ZnO}$ crystal. No other characteristic peaks corresponding to possible impurities, such as zinc nitrate or zinc hydroxide, are observed in the XRD patterns. 
Figure 2 shows the SEM micrographs of the laser irradiated $\mathrm{Si}$ substrates before and after the $\mathrm{ZnO}$ coating. Careful examination of Figure $2 \mathrm{a}$ and $\mathrm{b}$ makes clear that the $\mathrm{ZnO}$ coating did not affect the hierarchical micro- and nanostructure of the artificial surface; in both images, silicon spikes are clearly visible and distinct. This is reasonable since the roughness introduced by the $\mathrm{ZnO}$ layer is on the order of a few tens of nanometers while the spike dimensions are on the order of tens of microns (the peak of the spikes alone is close to $1 \mu \mathrm{m}$ wide) and their nanoroughness is on the order of $100 \mathrm{~nm}$. Therefore, the quantity of $\mathrm{ZnO}$ used is sufficient to create a very thin film on the surface of each spike but not in excess that would submerge them and make the roughness inefficient.

Photocatalytic Behavior. The photocatalytic mechanism of $\mathrm{ZnO}$ has been reported in previous works. ${ }^{37,41,49} \mathrm{UV}-$ vis spectroscopy was utilized to evaluate the photocatalytic behavior of the rough surfaces with the $\mathrm{ZnO}$ film coating as well as of the various controls. A custom-made cuvette was used that brought into contact the aqueous solution of methylene blue and the coated or noncoated surfaces during UV illumination. The absorbance as a function of wavelength for various UV illumination time intervals was monitored for each specimen; Figure 3a shows the absorption spectra for the specimen with the $\mathrm{ZnO}$ coating on top of the silicon spikes. The normalized integrated areas were calculated below such absorbance curves at the peak wavelength and the data are shown in Figure $3 b$ as a function of the UV illumination time. Figure $3 \mathrm{~b}$ illustrates the photocatalytic behavior of flat $\mathrm{Si}$ substrates, both bare and with a $\mathrm{ZnO}$ coating, along with the hierarchical surfaces (silicon spikes) both bare and with a $\mathrm{ZnO}$ coating.

The $\mathrm{ZnO}$ coated silicon spikes exhibit high photocatalytic activity when compared to a $\mathrm{ZnO}$ film on flat silicon. For the $\mathrm{ZnO}$ on the spikes, the degradation of $\mathrm{MB}$ reaches about $90 \%$ in only $60 \mathrm{~min}$ (even $\sim 70 \%$ degradation in only $30 \mathrm{~min}$ ), while for a $\mathrm{ZnO}$ on flat silicon the degradation is only $~ 30 \%$ after 60 min. This can be attributed to the high surface-to-volume ratio of the $\mathrm{ZnO}$ coated on the silicon spikes, in agreement with research results reported in the literature. ${ }^{41,50,51}$ The integrated area is proportional to the $\mathrm{MB}$ concentration; thus, analysis of the data of Figure $3 \mathrm{~b}$ with the equation

$$
\ln \left(I_{t} / I_{0}\right)=\ln \left(C_{t} / C_{0}\right)=-k t
$$

(see Experimental Section) can be used to extract an apparent rate constant. The data in Figure $3 \mathrm{~b}$ (especially for the $\mathrm{ZnO}$ film on silicon spikes) give a good linear fit, thus confirming that the photodegradation of $\mathrm{MB}$ over the studied photocatalysts follows first-order kinetics. The calculated apparent rate constant for the $\mathrm{ZnO}$ coated silicon spikes was 0.016 $\mathrm{min}^{-1}$, which is close to the values recorded in the literature. $^{42,52}$ Reference samples (flat $\mathrm{Si}$ substrate and $\mathrm{Si}$ spikes) without $\mathrm{ZnO}$ coatings were also characterized in terms of $\mathrm{MB}$ decolorization by means of $\mathrm{UV}$-vis absorption and showed that their photocatalytic activity was negligible.

Reversible Wettability Behavior. Figure 4 shows representative water drop images for the specimen with a $\mathrm{ZnO}$ coating onto a flat silicon surface (Figure $4 \mathrm{a}$ ) and onto a micro/nanostructured surface of silicon spikes (Figure 4b) following a cycle of UV irradiation and of subsequent heating. It can be clearly seen that, as the samples are exposed to UV illumination, they both become hydrophilic, while when the same samples are heated at $200{ }^{\circ} \mathrm{C}$ for $3 \mathrm{~h}$, an increase in their contact angle is recorded. It should be noted that the (a)

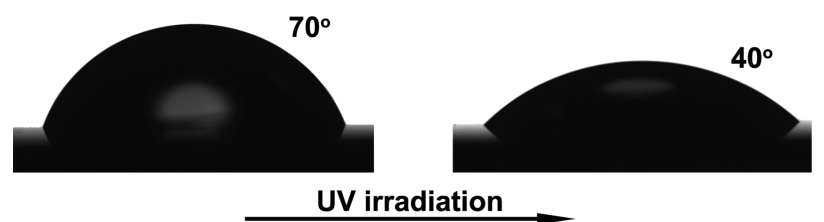

(b)

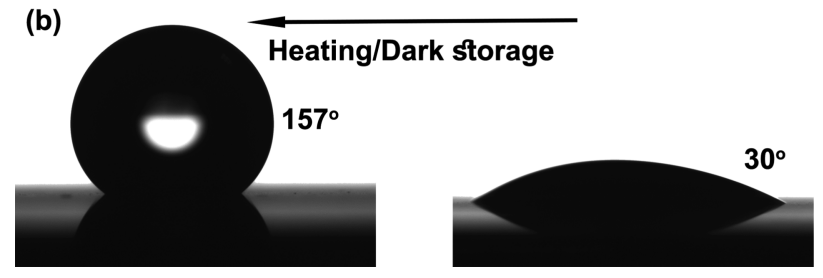

Figure 4. Photographs of representative water drops and the respective equilibrium contact angles on specimens with (a) $\mathrm{ZnO}$ coating onto a flat $\mathrm{Si}$ substrate and (b) $\mathrm{ZnO}$ coating onto a surface with silicon spikes. Drops are shown for the specimens following UV irradiation (on the right) and after thermal treatment at $200{ }^{\circ} \mathrm{C}$ (on the left).

hydrophobic behavior of the specimens can also be achieved by storing them in the dark, although this process requires time on the order of days. ${ }^{35,36}$ The contact angle of water on the $\mathrm{ZnO}$ coated flat silicon surfaces is measured at $\sim 70^{\circ}$ after heating while that on the $\mathrm{ZnO}$ coated silicon spikes gives values of $\sim 157^{\circ}$, illustrating their superhydrophobic behavior. The difference in the contact angle measurements between these two $\mathrm{ZnO}$ surfaces is due to the enhanced hierarchical roughness in the latter case. To the best of our knowledge, this is the first study presenting a superhydrophobic $\mathrm{ZnO}$ surface with a contact angle more than $150^{\circ}$. It is noted that our hierarchical surfaces did not exhibit low contact angle hysteresis (or, equivalently low sliding angle; data not shown). Water droplets stayed attached onto the surfaces even for angles as high as $90^{\circ}$. It is noted that the pinning force per unit length for a droplet on a surface is $F=\gamma_{\mathrm{LV}}\left(\cos \theta_{r}-\cos \theta_{a}\right)=\gamma_{\mathrm{LV}} \Delta(\cos \theta)$, with $\gamma_{\mathrm{LV}}$ the water surface tension and $\theta_{a}$ and $\theta_{r}$ the advancing and receding contact angles, respectively; the energy dissipated will, thus, scale as $\gamma_{\mathrm{LV}} R^{2} \Delta(\cos \theta)$, with $R$ the droplet radius. ${ }^{8}$ Thus, our surfaces are superhydrophobic with high water adhesion, similar to a number of biosurfaces like, e.g., the Rosa, cv. Bairage. ${ }^{12}$ This behavior indicates that the Si irradiated surfaces were not fully covered by the $\mathrm{ZnO}$ layers, which potentially could give space to the formation of hydrophilic defects that prevent droplets from rolling off. ${ }^{10,11}$

Figure 5 shows the water contact angles as a function of time of UV illumination (Figure 5a) and heating (Figure 5b), respectively, for a specimen with a $\mathrm{ZnO}$ coating onto a micro/ nanostructured surface of silicon spikes. When the surface is illuminated with UV, the contact angle decreases slowly with time until it reaches the superhydrophilic regime after about 50 $\mathrm{min}$. On the other hand, when the same surface is heated at 200 ${ }^{\circ} \mathrm{C}$, an apparently two-stage process is observed. The contact angle increases at a faster rate for early times reaching $\sim 120^{\circ}$ after $\sim 50 \mathrm{~min}$ whereas it, then, increases with a slower rate until it reaches a superhydrophobic state after $\sim 160$ min of exposure to heat. Other temperatures were also tested. Lower temperatures caused a rapid decrease in efficiency while higher temperatures did not make the process much faster or more efficient. This makes the whole process affordable in energy 

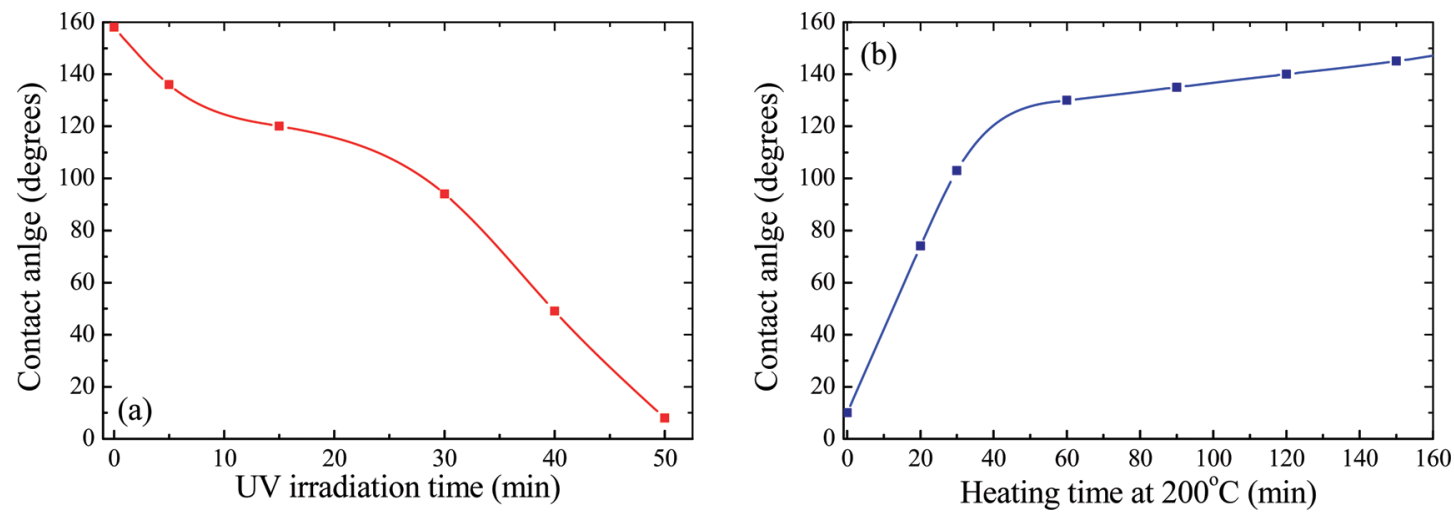

Figure 5. Dependence of the water contact angle on a surface with a $\mathrm{ZnO}$ coating on top of the silicon spikes following (a) UV irradiation and (b) heating at $200{ }^{\circ} \mathrm{C}$ for various times.

cost and convenient since it does not require any sophisticated equipment for heating.

Stability of the Behavior. In order to study the reproducibility and the stability of the system, specimens have been subjected to cycles of UV irradiation and thermal heating and their wettability is investigated (Figure 6). The

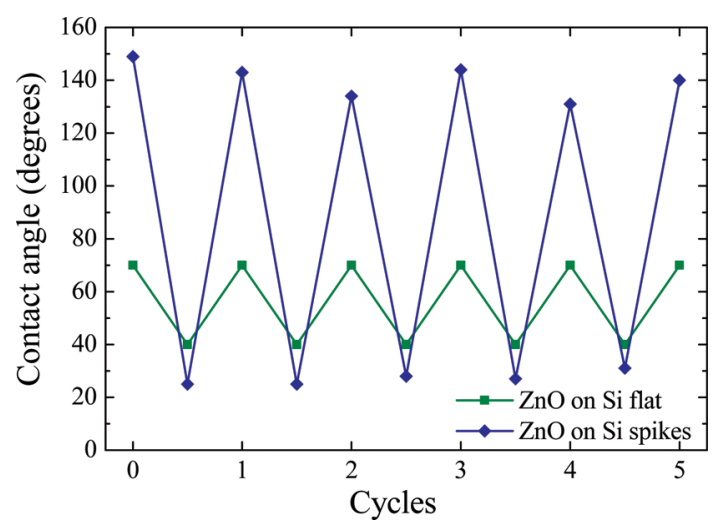

Figure 6. Average contact angle values of water droplets situated on specimens with $\mathrm{ZnO}$ coating onto a flat $\mathrm{Si}$ substrate (squares) and $\mathrm{ZnO}$ coating onto a surface with silicon spikes (diamonds) for five irradiation cycles of UV irradiation and $3 \mathrm{~h}$ thermal heating at $200^{\circ} \mathrm{C}$.

water contact angle data are shown for the specimens with a $\mathrm{ZnO}$ coating onto a surface with silicon spikes and the one with a $\mathrm{ZnO}$ coating onto a flat silicon substrate for five cycles of $\mathrm{UV}$ illumination and heating. A responsive behavior is observed for the case of the $\mathrm{ZnO}$ coated flat specimen with contact angle values fluctuating within a narrow region between $40^{\circ}$ and $70^{\circ}$. On the contrary, the $\mathrm{ZnO}$ coated hierarchically roughened specimen exhibits a very wide range in responsiveness ranging from around $20^{\circ}$ to a region very close to $150^{\circ}$. Both reversibility and reproducibility prove the efficiency and endurance of the surfaces, which is very important for practical applications.

It has been reported in the literature that there is a possibility for photocorrosion under UV irradiation of the $\mathrm{ZnO}$ catalyst; ${ }^{49}$ this is more prone to happen for ultrathin $(20-70 \mathrm{~nm})$ films of $\mathrm{ZnO}$. Thus, we have performed tests of the present system for the stability and reproducibility of the photocatalytic behavior. For that, cycles of both wettability and photocatalysis measurements were performed and the performance is illustrated in Table 1.
Table 1. Repeatability of the Specimen Performance

\begin{tabular}{|c|c|c|c|c|c|}
\hline & wettal & ility & & hotocatalysi & \\
\hline & & & $\begin{array}{l}\% \text { degra } \\
\text { methyl }\end{array}$ & $\begin{array}{l}\text { ation of } \\
\text { le blue }\end{array}$ & \\
\hline & $\begin{array}{l}\text { after heating } \\
\text { in } 200{ }^{\circ} \mathrm{C}\end{array}$ & $\begin{array}{l}\text { after UV } \\
\text { irradiation }\end{array}$ & $\begin{array}{l}\text { after } 20 \\
\min \\
\text { irradiation }\end{array}$ & $\begin{array}{c}\text { after } 60 \\
\text { min } \\
\text { irradiation }\end{array}$ & $\begin{array}{l}\text { reaction } \\
\text { constant } \\
(k)\end{array}$ \\
\hline $\begin{array}{l}\text { 1st } \\
\text { cycle }\end{array}$ & $157^{\circ}$ & $10^{\circ}$ & 22 & 86 & $0.016 \mathrm{~s}^{-1}$ \\
\hline $\begin{array}{l}\text { 2nd } \\
\text { cycle }\end{array}$ & $151^{\circ}$ & $20^{\circ}$ & 21 & 84 & $0.016 \mathrm{~s}^{-1}$ \\
\hline
\end{tabular}

According to the results the surface maintains the reversible wettability behavior after photocatalysis as well as its superhydrophobic features. Furthermore, the second cycle of photocatalysis proved to be as efficient as the first one, without any reduction of the reaction rate constant. Therefore, the system maintained its efficiency after repeated wettabilityphotocatalysis cycles proving its reproducibility and stability. Such a biresponsive structure could be the basis for a variety of applications in the future.

\section{CONCLUSIONS}

A multifunctional surface with a $\mathrm{ZnO}$ coating deposited onto a hierarchically roughened surface has been fabricated with a twostep process. The wettability and the photocatalytic activity of the surfaces have been investigated in detail as a function of time. High photocatalytic activity is achieved with a $\sim 90 \%$ decolorization of a model dye in $\sim 60 \mathrm{~min}$. The systems exhibit a reversible wettability behavior from superhydrophilic (upon UV irradiation) to superhydrophobic (upon heating). The stability of the behavior is investigated extensively and the system proves to be quite stable. To the best of our knowledge, this is the first work on the development of surfaces with both high photocatalytic activity and reversible wettability behavior from superhydrophobic to superhydrophilic. The combination of photocatalysis with reversible wettability with a single coating makes the system appropriate for a variety of applications, such as self-cleaning surfaces, air purification, marine coatings, or fog-proofing.

\section{AUTHOR INFORMATION}

\section{Corresponding Author}

*E-mail: spiros@iesl.forth.gr. Phone: +30-2810-391466. Fax: + 30-2810-391305. 


\section{Notes}

The authors declare no competing financial interest.

\section{ACKNOWLEDGMENTS}

This research was partially supported by the European Union (European Social Fund, ESF) and Greek national funds through the "ARISTEIA II" Action (SMART_SURF) of the Operational Programme "Education and Lifelong Learning", NSRF 2007-2013, via the General Secretariat for Research \& Technology, Ministry of Education and Religious Affairs, Greece. This work was also supported by the European Research Infrastructure LASERLAB EUROPE (Grant Agreement No. 228334). We would like to acknowledge the interaction with Dr. Emmanuel Stratakis on the surface micro/nanostructuring. We want to thank Mrs. Aleka Manousaki for her assistance with the SEM measurements.

\section{REFERENCES}

(1) Anastasiadis, S. H. Development of Functional Polymer Surfaces with Controlled Wettability. Langmuir 2013, 29, 9277-9290.

(2) Bhushan, B.; Jung, Y. C.; Koch, K. Micro-, Nano- and Hierarchical Structures for Superhydrophobicity, Self-Cleaning and Low Adhesion. Philos. Trans. R. Soc., A 2009, 367, 1631-1672.

(3) Zorba, V.; Stratakis, E.; Barberoglou, M.; Spanakis, E.; Tzanetakis, P.; Anastasiadis, S. H.; Fotakis, C. Biomimetic Artificial Surfaces Quantitatively Reproduce the Water Repellency of a Lotus Leaf. $A d v$. Mater. 2008, 20, 4049-4054.

(4) Blossey, R. Self-Cleaning Surfaces-Virtual Realities. Nat. Mater. 2003, 2, 301-306.

(5) Callies, M.; Quéré, D. Soft Matter 2005, 1, 55.

(6) Nakajima, A.; Fujishima, A.; Hashimoto, K.; Watanabe, T. Preparation of Transparent Superhydrophobic Boehmite and Silica Films by Sublimation of Aluminum Acetylacetonate. Adv. Mater. 1999, $11,1365-1368$.

(7) Wang, B.-B.; Feng, J.-T.; Zhao, Y.-P.; Yu, T. X. Fabrication of Novel Superhydrophobic Surfaces and Water Droplet Bouncing Behavior - Part 1: Stable ZnO-PDMS Superhydrophobic Surface with Low Hysteresis Constructed Using $\mathrm{ZnO}$ Nanoparticles. J. Adhes. Sci. Technol. 2010, 24, 2693-2705.

(8) Wang, B.-B.; Zhao, Y.-P.; Yu, T. Fabrication of Novel Superhydrophobic Surfaces and Droplet Bouncing Behavior - Part 2: Water Droplet Impact Experiment on Superhydrophobic Surfaces Constructed Using ZnO Nanoparticles. J. Adhes. Sci. Technol. 2011, 25, 93-108.

(9) Wang, Z.; Wang, F.-C.; Zhao, Y.-P. Tap Dance of a Water Droplet. Proc. R. Soc. London, Ser. A 2012, 468, 2485-2495.

(10) Chang, F.-M.; Hong, S.-J.; Sheng, Y.-J.; Tsao, H.-K. High Contact Angle Hysteresis of Superhydrophobic Surfaces: Hydrophobic Defects. Appl. Phys. Lett. 2009, 95, 064102.

(11) Wang, L.; Wei, J.; Su, Z. Fabrication of Surfaces with Extremely High Contact Angle Hysteresis from Polyelectrolyte Multilayer. Langmuir 2011, 27, 15299-15304.

(12) Bhushan, B. Bioinspired Structured Surfaces. Langmuir 2012, 28, 1698-1714.

(13) Ueda, E.; Levkin, P. A. Emerging Applications of Superhydrophilic-Superhydrophobic Micropatterns. Adv. Mater. 2013, 25, 1234-1247.

(14) Barthlott, W.; Neinhuis, C. Purity of the Sacred Lotus, or Escape from Contamination in Biological Surfaces. Planta 1997, 202, 1-8.

(15) Fürstner, R; Barthlott, W.; Neinhuis, C.; Walzel, P. Wetting and Self-Cleaning Properties of Artificial Superhydrophobic Surfaces. Langmuir 2005, 21, 956-961.

(16) Liu, K.; Jiang, L. Bio-Inspired Design of Multiscale Structures for Function Integration. Nano Today 2011, 6, 155-175.

(17) Hsu, S.-T.; Wang, H.; Satoh, G.; Yao, Y. L. Applications of Surface Structuring with Lasers. Icaleo 2011, 1095-1104.
(18) Her, T.-H.; Finlay, R. J.; Wu, C.; Deliwala, S.; Mazur, E. Microstructuring of Silicon with Femtosecond Laser Pulses. Appl. Phys. Lett. 1998, 73, 1673.

(19) Zhang, D.; Chen, F.; Yang, Q.; Yong, J.; Bian, H.; Ou, Y.; Si, J.; Meng, X.; Hou, X. A Simple Way to Achieve Pattern-Dependent Tunable Adhesion in Superhydrophobic Surfaces by a Femtosecond Laser. ACS Appl. Mater. Interfaces 2012, 4, 4905-4912.

(20) Zorba, V.; Persano, L.; Pisignano, D.; Athanassiou, a; Stratakis, E.; Cingolani, R.; Tzanetakis, P.; Fotakis, C. Making Silicon Hydrophobic: Wettability Control by Two-Lengthscale Simultaneous Patterning with Femtosecond Laser Irradiation. Nanotechnology 2006, $17,3234-3238$

(21) Barberoglou, M.; Zorba, V.; Stratakis, E.; Spanakis, E.; Tzanetakis, P.; Anastasiadis, S. H.; Fotakis, C. Bio-Inspired Water Repellent Surfaces Produced by Ultrafast Laser Structuring of Silicon. Appl. Surf. Sci. 2009, 255, 5425-5429.

(22) Wang, S.; Song, Y.; Jiang, L. Photoresponsive Surfaces with Controllable Wettability. J. Photochem. Photobiol., C 2007, 8, 18-29.

(23) Feng, X.; Jiang, L. Design and Creation of Superwetting/ antiwetting Surfaces. Adv. Mater. 2006, 18, 3063-3078.

(24) Rosario, R.; Gust, D.; Hayes, M.; Jahnke, F.; Springer, J.; Garcia, A. A. Photon-Modulated Wettability Changes on Spiropyran-Coated Surfaces. Langmuir 2002, 18, 8062-8069.

(25) Liu, H.; Feng, L.; Zhai, J.; Jiang, L.; Zhu, D. Reversible Wettability of a Chemical Vapor Deposition Prepared ZnO Film between Superhydrophobicity and Superhydrophilicity. Langmuir 2004, 20, 5659-5661.

(26) Irie, H.; Ping, T. S.; Shibata, T.; Hashimoto, K. Reversible Control of Wettability of a $\mathrm{TiO}$ [sub 2] Surface by Introducing Surface Roughness. Electrochem. Solid-State Lett. 2005, 8, D23.

(27) Crevoisier, G. D. Switchable Tackiness and Wettability of a Liquid Crystalline Polymer. Science (Washington, DC, U. S.) 1999, 285, $1246-1249$

(28) Fu, Q.; Rao, G. V. R.; Basame, S. B.; Keller, D. J.; Artyushkova, K.; Fulghum, J. E.; López, G. P. Reversible Control of Free Energy and Topography of Nanostructured Surfaces. J. Am. Chem. Soc. 2004, 126, 8904-8905.

(29) Sun, T.; Wang, G.; Feng, L.; Liu, B.; Ma, Y.; Jiang, L.; Zhu, D. Reversible Switching between Superhydrophilicity and Superhydrophobicity. Angew. Chem., Int. Ed. 2004, 43, 357-360.

(30) Lahann, J.; Mitragotri, S.; Tran, T.-N.; Kaido, H.; Sundaram, J.; Choi, I. S.; Hoffer, S.; Somorjai, G. A.; Langer, R. A Reversibly Switching Surface. Science 2003, 299, 371-374.

(31) Krupenkin, T. N.; Taylor, J. A.; Schneider, T. M.; Yang, S. From Rolling Ball to Complete Wetting: The Dynamic Tuning of Liquids on Nanostructured Surfaces. Langmuir 2004, 20, 3824-3827.

(32) Yu, X.; Wang, Z.; Jiang, Y.; Shi, F.; Zhang, X. Reversible pHResponsive Surface: From Superhydrophobicity to Superhydrophilicity. Adv. Mater. 2005, 17, 1289-1293.

(33) Stratakis, E.; Mateescu, A.; Barberoglou, M.; Vamvakaki, M.; Fotakis, C.; Anastasiadis, S. H. From Superhydrophobicity and Water Repellency to Superhydrophilicity: Smart Polymer-Functionalized Surfaces. Chem. Commun. 2010, 46, 4136.

(34) Minko, S.; Müller, M.; Motornov, M.; Nitschke, M.; Grundke, K.; Stamm, M. Two-Level Structured Self-Adaptive Surfaces with Reversibly Tunable Properties. J. Am. Chem. Soc. 2003, 125, 38963900.

(35) Papadopoulou, E. L.; Barberoglou, M.; Zorba, V.; Manousaki, A.; Pagkozidis, A.; Stratakis, E.; Fotakis, C. Reversible Photoinduced Wettability Transition of Hierarchical ZnO Structures. J. Phys. Chem. C 2009, 113, 2891-2895.

(36) Papadopoulou, E. L.; Zorba, V.; Pagkozidis, a.; Barberoglou, M.; Stratakis, E.; Fotakis, C. Reversible Wettability of $\mathrm{ZnO}$ Nanostructured Thin Films Prepared by Pulsed Laser Deposition. Thin Solid Films 2009, 518, 1267-1270.

(37) Kenanakis, G.; Stratakis, E.; Vlachou, K.; Vernardou, D.; Koudoumas, E.; Katsarakis, N. Light-Induced Reversible Hydrophilicity of $\mathrm{ZnO}$ Structures Grown by Aqueous Chemical Growth. Appl. Surf. Sci. 2008, 254, 5695-5699. 
(38) Feng, C. L.; Zhang, Y. J.; Jin, J.; Song, Y. L.; Xie, L. Y.; Qu, G. R.; Jiang, L.; Zhu, D. B. Reversible Wettability of Photoresponsive Fluorine-Containing Azobenzene Polymer in Langmuir-Blodgett Films. Langmuir 2001, 17, 4593-4597.

(39) Wang, Y.; Li, X.; Wang, N.; Quan, X.; Chen, Y. Controllable Synthesis of $\mathrm{ZnO}$ Nanoflowers and Their Morphology-Dependent Photocatalytic Activities. Sep. Purif. Technol. 2008, 62, 727-732.

(40) Yang, Y. H.; Li, Z. Y.; Wang, B.; Wang, C. X.; Chen, D. H.; Yang, G. W. Self-Assembled ZnO Agave-like Nanowires and Anomalous Superhydrophobicity. J. Phys.: Condens. Matter 2005, 17, 5441-5446.

(41) Kenanakis, G.; Vernardou, D.; Katsarakis, N. Light-Induced SelfCleaning Properties of $\mathrm{ZnO}$ Nanowires Grown at Low Temperatures. Appl. Catal., A 2012, 411-412, 7-14.

(42) Kenanakis, G.; Katsarakis, N. ZnO Nanowires on Glass via Chemical Routes: A Prospective Photocatalyst for Indoors Applications. J. Environ. Chem. Eng. 2014, 2, 1416-1422.

(43) Kenanakis, G.; Pervolaraki, M.; Giapintzakis, J.; Katsarakis, N. The Use of Pulsed Laser Deposited Seed Layers for the Aqueous Solution Growth of Highly Oriented $\mathrm{ZnO}$ Nanowires on Sapphire Substrates at $95^{\circ} \mathrm{C}$ : Study of Their Photocatalytic Activity in Terms of Octadecanoic (stearic) Acid Degradation. Appl. Catal., A 2013, 467, $559-567$.

(44) Zhang, T.; Oyama, T.; Aoshima, A.; Hidaka, H.; Zhao, J.; Serpone, N. Photooxidative N-Demethylation of Methylene Blue in Aqueous $\mathrm{TiO}_{2}$ Dispersions under UV Irradiation. J. Photochem. Photobiol., A 2001, 140, 163-172.

(45) Kwon, C. H.; Shin, H.; Kim, J. H.; Choi, W. S.; Yoon, K. H. Degradation of Methylene Blue via Photocatalysis of Titanium Dioxide. Mater. Chem. Phys. 2004, 86, 78-82.

(46) Houas, A. Photocatalytic Degradation Pathway of Methylene Blue in Water. Appl. Catal., B 2001, 31, 145-157.

(47) Kenanakis, G.; Katsarakis, N. Chemically Grown TiO2 on Glass with Superior Photocatalytic Properties. J. Environ. Chem. Eng. 2014, 2, $1748-1755$.

(48) Anastasiadis, S. H.; Hatzikiriakos, S. G. The Work of Adhesion of Polymer/wall Interfaces and Its Association with the Onset of Wall Slip. J. Rheol. (Melville, NY, U. S.) 1998, 42, 795.

(49) Cao, Y.-Q.; Chen, J.; Zhou, H.; Zhu, L.; Li, X.; Cao, Z.-Y.; Wu, D.; Li, A.-D. Photocatalytic Activity and Photocorrosion of Atomic Layer Deposited ZnO Ultrathin Films for the Degradation of Methylene Blue. Nanotechnology 2015, 26, 024002.

(50) Chen, L. J.; Ma, H.; Chen, K. C.; Fan, W.; Cha, H. R.; Lee, Y. I.; Qian, D. J.; Hao, J.; Liu, H. G. Synthesis and Assembly of Catalytically Active Platinum-Doped Polymer Nanocomposites at the Liquid/liquid Interface. Colloids Surf., A 2011, 386, 141-150.

(51) Hong, R.; Pan, T.; Qian, J.; Li, H. Synthesis and Surface Modification of $\mathrm{ZnO}$ Nanoparticles. Chem. Eng. J. 2006, 119, 71-81.

(52) Mills, A.; Wang, J. Simultaneous Monitoring of the Destruction of Stearic Acid and Generation of Carbon Dioxide by Self-Cleaning Semiconductor Photocatalytic Films. J. Photochem. Photobiol., A 2006, 182, 181-186. 